1. MBBS, FCPS

Senior registrar, OB/GYN-III, Jinnah hospital, Lahore

2. MBBS, FCPS

Senior registrar,

Madina teaching hospital,

Faisalabad.

3. MBBS, FCPS

Senior registrar,

Azra Naheed medical college,

Lahore.

Correspondence Address:

Dr. Quddsia Tanveer

MBBS, FCPS.

Senior registrar, OB/GYN-III,

Jinnah hospital, Lahore

Address: 344, G4, Wapda

Town, Phase-I, Lahore.

drqudsia@live.com

Article received on: 02/07/2016

Accepted for publication:

15/09/2016

Received after proof reading:

14/11/2016

\title{
LABOR AT TERM; \\ COMPARISON OF OBSTETRIC OUTCOME BETWEEN PRIMIGRAVIDA AND MULTIGRAVIDA PRESENTING IN LABOARTERY. \\ drqudsia@live.com
}

Dr. Quddsia Tanveer ${ }^{1}$, Dr. Anees Fatima ${ }^{2}$, Dr. Ummara Maqsood Sana ${ }^{3}$

ABSTRACT... Objectives: To compare the obstetric outcome between primigravida and multigravida presenting in labor at term. Study Design: Cross sectional study. Period: Six months from Jan 2013 to Jun 2013. Setting: Obs/Gynae unit III, Jinnah hospital, Lahore. Patients and methods: 800 patients were included in the study which comprised 400 of primigravida and 400 of multigravida. Patients having single, alive fetus with cephalic presentation at 37-41 weeks were included in the study. Those having recurrent miscarriages, parity $>5$, antepartum hemorrhage, previous uterine scars and significant medical illness were excluded from the study. The data was collected on specially designed proforma. Observations mode of delivery including the indication of cesarean section or instrumental vaginal delivery if applicable. Maternal complications such as postpartum hemorrhage along with its cause, retained placenta and uterine inversion were also recorded. Fetal and neonatal observations included CTG abnormalities, oligohydramnios, low birth weight, macrosomia, Apgar score $<7$ at 5 minutes, NICU admission, fresh still birth and early neonatal death. Results: Mean age was $25.57+3.46$ years in primigravida women while it was $25.75+3.44$ years in multigravida group. CTG abnormalities (15.5\% VS $4.25 \%$ ), instrumental deliveries (9.75\% VS 1\%), cesarean section $(15.25 \%$ VS $1 \%)$ and postpartum hemorrhage (5.7\% VS $1.75 \%)$ were commoner in primigravida women. In addition, NICU admissions, low birth weight babies and a low Apgar score at 5-minute were also commoner in primigravida women. Conclusion: Nulliparous women are at greater risk of labor abnormalities, fetal distress, instrumental deliveries, cesarean section, postpartum hemorrhage and neonatal morbidity. These adverse factors should therefore be looked for and treated well in time.

Key words: $\quad$ Obstetric outcome, primigravida, multigravida

Article Citation: Tanveer Q, Fatima A, Sana UM. Labor at term; comparison of obstetric outcome between primigravida and multigravida presenting. Professional Med J 2016;23(11):1354-1357. DOI: 10.17957/TPMJ/16.3553

\section{INTRODUCTION}

Labor carries a significant concern not only for the mother but also for the fetus. The impact is even more in the under developed nations of the world where most of the women deliver at home or at places where even the minimum health care amenities are not available. Under these situations, the women and their babies may encounter a variety of complications which at their extreme may lead to fetal, neonatal or maternal mortality. Therefore, there is a huge need to identify women whose pregnancy is at increased risk of complications which is a pivotal part of antenatal screening. ${ }^{1,2}$ It is a real obligation to provide them necessary health care services to rescue and save their lives. ${ }^{3}$ Factors contributing to pregnancy complications are diverse including young age, lack of cognizance regarding provision of antenatal care, health education deficiency, negligence, monetary limitations, ecological \& traditional biases, involvement of male members in maternal health care, deprived nutritional status of young pregnant women like high prevalence of anaemia, conveyance issues, lesser focus on patient counselling before decision of mode of delivery particularly in primiparous are the important explanations behind high frequency of these complications. Moreover, Women facing these problems are by all means bound to receive care in in insufficient facilities.

The impact of first delivery on forthcoming obstetric record and delivery decision by patient and the attending obstetrician is unmatched. ${ }^{5}$ Cesarean section rates fluctuate among obstetricians 
due to various indications in low risk pregnant population. ${ }^{6}$ Since decision for labor and mode of delivery has a great bearing on future obstetrics of a woman, therefore cautious monitoring and a sensible decision for labor and mode of delivery is essential from the attending doctor. ${ }^{7}$

A primigravida's labor is way different from that of a multigravida. The distinguishing feature in a primigravida is lengthier duration when compared with multigravida. Low birth weight infants are more frequent in primigravida group which is responsible for higher morbidity and mortality risks. Furthermore, the likelihood of perineal trauma is higher in primigravida as a consequence of episiotomy or spontaneous tears. Another important aspect is the fact that intrapartum risk assessment usually depends upon past obstetrical performance which is obviously not pertinent to primigravida. Besides all these facts, the risk of adverse outcome with parity does not show a steady pattern. ${ }^{8}$ The objective of this study was to compare the obstetric outcome between primigravida and multigravida presenting at term in labor.

\section{PATIENTS AND METHOD}

The study was conducted from Jan 2013 to Jun 2013 at the Ob/Gyn unit III, Jinnah hospital, Lahore. 800 patients were included in the study comprising 400 of primigravida and 400 of multigravida. The sampling technique was convenient non probability. Patients having single, alive fetus with cephalic presentation at 37-41 weeks were included in the study. Those having recurrent miscarriages, parity $>5$, antepartum hemorrhage, previous uterine scars and significant medical illness were excluded from the study. The data was collected on specially designed proforma. Observations regarding maternal age, mode of delivery including the indication of cesarean section or instrumental vaginal delivery were done. Maternal complications such as postpartum hemorrhage along with its cause, retained placenta and uterine inversion were also recorded. Fetal and neonatal observations included oligohydramnios (diagnosed on ultrasound), abnormal CTG, low birth weight $(<2.5 \mathrm{~kg})$, macrosomia $(>4 \mathrm{~kg})$,
Apgar score $<7$ at 5 minutes, NICU admission and early neonatal death. Percentages were calculated for the above except maternal age for which mean + SD were calculated for both groups. Chi square test was used for qualitative variables to assess any difference between the two groups. A p-value of $<0.05$ was considered significant.

\section{RESULTS}

The mean ages in primigravida and multigravida group were $25.57+3.46$ and $25.75+3.44$ years respectively. CTG abnormalities were more in primigravida group than the multiparous women (15.5\% VS 4.25\%). Oligohydramnios was common among multigravida $(11.5 \%, \mathrm{n}=$ 46) than primigravida $(9 \%, n=36)$ however the difference was not statistically significant with $p$ value $=0.140$ (Figure-1). 9.75\% $(n=39)$ of primigravida while $1 \% \quad(n=4)$ of multigravida women underwent instrumental vaginal delivery ( $p$ value $<0.0001$ ). Indications of instrumental deliveries among primigravida were fetal distress in 30 cases, maternal exhaustion in 4 and poor progress in 5 cases. 3 of the 4 multigravida underwent instrumental delivery due to fetal distress while one due to poor progress in second stage of labor. $15.25 \%$ $(n=61)$ of primigravida women while $1 \%(n=4)$ of multigravida women had to undergo cesarean section (Table-I). Indications of cesarean section in primigravida group were failure to progress in $42.6 \%(n=26)$ and fetal distress in $57.4 \%(n=35)$ of total women undergoing abdominal delivery (Figure-2). Indications of cesarean section in multigravida group were fetal distress in 3 women and secondary arrest of cervical dilatation in 1 woman. $5.7 \%(n=23)$ of primigravida women had postpartum hemorrhage while this percentage was $1.75 \%(n=7)$ among multigravida group $(p$ value $<0.0001$ ). The major cause of $\mathrm{PPH}$ was lower genital tract injuries in primigravida while uterine atony in multigravida group. There were $4(1 \%)$ cases of retained placenta in primigravida group while only 1 case of retained placenta in multigravida group ( $p$ value $=0.002$ ). One case of $3^{\text {rd }}$ degree perineal tear was observed in primigravida group while no such complication arose in the multiparous group. No case of 
uterine inversion or maternal mortality observed in both.

\begin{tabular}{|l|c|c|c|}
\hline \multicolumn{1}{|c|}{ variable } & $\begin{array}{c}\text { Primigravida } \\
\text { N (\%) }\end{array}$ & $\begin{array}{c}\text { Multigravida } \\
\text { N (\%) }\end{array}$ & p-value \\
\hline $\begin{array}{l}\text { Instrumental } \\
\text { delivery }\end{array}$ & $39(9.75 \%)$ & $4(1 \%)$ & 0.0001 \\
\hline $\begin{array}{l}\text { Cesarean } \\
\text { section }\end{array}$ & $61(15.25 \%)$ & $4(1 \%)$ & 0.0001 \\
\hline PPH & $23(5.7 \%)$ & $7(1.75 \%)$ & $<0.0001$ \\
\hline $\begin{array}{l}\text { Retained } \\
\text { placenta }\end{array}$ & $4(1 \%)$ & $1(0.25 \%)$ & 0.002 \\
\hline $\begin{array}{l}\text { Total no. of } \\
\text { patients }\end{array}$ & 400 & 400 & \\
\hline
\end{tabular}

Table-I. Comparison of maternal complications between the two groups.

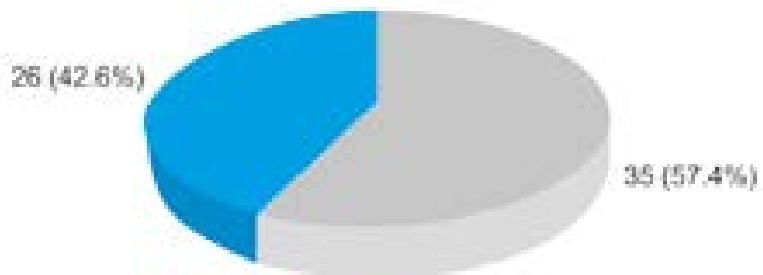

- Fetal distress - Falure to progress

Figure-1. Comparison of fetal and neonatal complications.

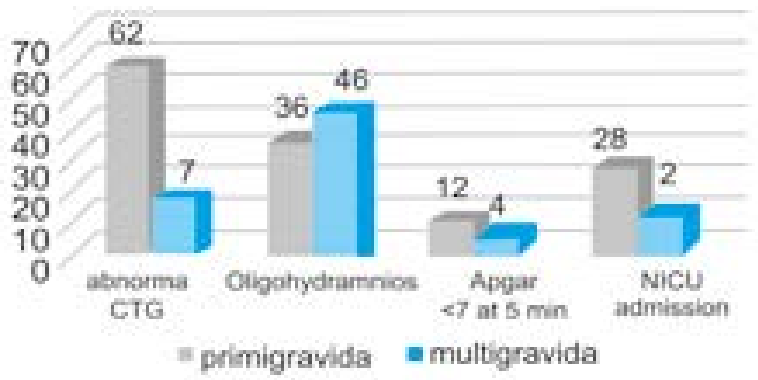

Figure-2. Indications of cesarean section in primigravida

Neonatal 5-minute Apgar score of $<7$ was seen in $3 \%(n=12)$ of primigravida group while $1 \%$ $(n=4)$ in multigravida group ( $p$ value $=0.157$ ) Neonatal weight of $>4 \mathrm{~kg}$ was seen in $2 \%$ $(n=8)$ of primigravida while it was $4 \%(n=16)$ in multigravida group ( $p$-value $=0.045)$. Neonatal weight of $<2.5 \mathrm{~kg}$ was seen in $10 \% \quad(n=40)$ of primigravida while it was $2 \%(n=8)$ in the comparison group ( $p$ value $<0.0001$ ).

$7 \%(n=28)$ of neonates in primigravida group needed NICU admission while this percentage was $3 \%(n=12)$ in multigravida group ( $p$ value $<$ 0.0001 ). One case of early neonatal death was observed in primigravida group.

\section{DISCUSSION}

The link of parity and pregnancy outcome has been of great worry for obstetricians since long. The association between parity and pregnancy outcomes have been depicted by various studies. Adverse obstetric outcome is significantly associated with nulliparity especially in the context of developing world where the problem is further augmented by variety of other factors contributing towards poor maternal health. ${ }^{9,10}$ Nulliparity may impart such risks through higher rates of abdominal deliveries and greater probability of obstructed labor. ${ }^{1}$ Also, because of the fact that nulliparous women have no obstetrical history, their risk assessment is deficient thereby increasing their likelihood of complications. Our study demonstrates that the nulliparity is associated with many obstetric risks. In this study, CTG abnormalities were more in primigravida group than the multiparous women. These results are consistent with the study performed by Hashim $\mathrm{N}$ et al. ${ }^{5}$ More women in nulliparous group underwent instrumental deliveries and cesarean section. These results are supported by the studies performed by Mbukani R et al. ${ }^{11}$

Postpartum hemorrhage is a serious complication of $3^{\text {rd }}$ stage of labor. In this study, it was observed to be higher in nulliparous than in multiparous women. However, the etiology is different in the two groups. These findings are consistent with the study performed by kremer MS et al and others.5, ${ }^{12}$ Uterine atony was the main cause in multiparous women while lower genital tract injuries were commoner among nulliparous women. One case of $3^{\text {rd }}$ degree perineal tear was seen in primigravida group while no such case occurred in multiparous women. There were more cases of retained placenta in nulliparous group than multiparous women. According to an estimate of $\mathrm{WHO}$, approximately $11 \%$ of new born babies suffer from low birth weight at term. ${ }^{13}$ Low birth weight babies were seen more frequently in primigravidas $(10 \% n=40)$ than multigravidas $(2 \% n=8)$. The results are statistically significant. Kaur $\mathrm{J}$ et al also observed higher rates among primigravidas however the percentage was higher than that observed in the current study. ${ }^{14} \mathrm{~A}$ statistically insignificant higher rate of 
oligohydramnios was noted among multigravidas in the current study. The results are somewhat contrary to those observed by Kaur $\mathrm{J}$ et al where oligohydramnios was seen more frequently in primigravida group. In a study conducted by Nazlime $\mathrm{N}$ et al, multigravida group was prevalent among those having oligohydramnios. ${ }^{15}$ It was observed that poor Apgar score and NICU admission were higher in primigravida group than that of multiparous group.

This study is not without limitations being a hospital based observational study. There is a definite need of further research focusing more on the interventions to reduce the rate of various complication encountered.

\section{CONCLUSION}

Nulliparous women are at greater risk of labor abnormalities, fetal distress, instrumental deliveries, cesarean section, postpartum hemorrhage and neonatal morbidity. Such risk factors should be sought after and dealt well in time.

Copyright(C) 15 Sep, 2016.

\section{REFERENCES}

1. Geidam AD, Ibrahim SM, Oummate Z, Audu BM. Pregnancy outcome among nulliparous women at Maidugura Teaching Hospital, North eastern Nigeria: a retrospective cohort study. British Journal of Medicine and medical research 2014: 4(21).

2. Flenady V, Wojcieszek AM, Middleton P, et al, for The Lancet Ending Preventable Stillbirths study group and The Lancet Stillbirths in High Income Countries Investigator Group. Stillbirths: recall to action in high-income countries. Lancet 2016; published online Jan 18. http://dx.doi.org/10.1016/S0140-6736 (15)01020-X.

3. Ojiyi E, Anozie U, Dike E, Okeudo C, Anolue F et al. Pregnancy outcome in primigravidae in a tertiary care hospi-tal: A three year review. The internet journal of Gynecology and obstetrics 2012; 16(1).
4. Gonied AS. Maternal complications and perinatal outcomes in booked and un booked mothers. Journal of American Sciences 2011; 7:792.

5. Hashim N, Naqvi S, Khanam M, jafry HF. Primiparity as an intrapartum obstetric risk factor. JPMA: 2012;

6. Abu Omar AA, Abu Anza SH. Frequency rate and indications of cesarean section at prince Zaid Bin Hussein Hospital- Jordan. JRMS Mar 2012; 19(1):8286.

7. Stavrou EP, Ford JB, Shand AW et al. Epidemiology and trends for cesarean sevtion births in New South Wales, Australia: a population - based study. BMC pregnancy child birth $2011 ; 20 ; 11(1): 8$.

8. Hajo IJ Wildschut. Constitutional and environmental factors leading to a high risk pregnancy. High risk pregnan-cy management options, 4.

9. Pell C, Menaca A, Were F, Afrah NA, Chatio S, MandaTaylor L et al. PLoS One. 2013; 8(1): e53747.

10. Andrew EVW, Pell C, Anguin A, Auwun A, Daniels J et al. Factors affecting attendance at and timing of formal antenatal care: Results from a qualitative study in Madang. Papua New Guinea. PLoS One. 2014; 9(5): e93025.

11. Mbukani R, kakoma JB. Is nulliparity a risk factor for poor obstetric and neonatal outcome in Rwandan district hospitals? A prospective observational study at Muhina district hospital. Rwanda medical journal Mar 2012; 69(1): 50-53.

12. Kramer MS, Dahhou M, Vallerand D, Liston R, Joseph KS. Risk factors for postpartum hemorrhage: can we ex-plain the recent temporal increase? J Obstet Gynaecol Can 2011; 33: 810-9.

13. Chakraborty P. caughey AB, Laguardia JC, Escobar GJ. J Perinatol 2012; 32: 260.

14. Kaur J, Kaur K. Obstetric complications: primiparity VS multiparity. Euro J. Exp. Bio 2012; 2(5): 1462-1468.

15. Nazlime N, Fatima B. Oligohydramnios at third trimester and perinatal outcome. Bangladesh Journal of medical science 2012; 11: 33-36.

\begin{tabular}{|c|l|l|l|}
\hline \multicolumn{3}{|c|}{ AUTHORSHIP AND CONTRIBUTION DECLARATION } \\
\hline Sr. \# & \multicolumn{1}{|c|}{ Author-s Full Name } & Contribution to the paper & Author=s Signature \\
\hline 1 & Dr. Quddsia Tanveer & 1st Author \\
\hline 2 & Dr. Anees Fatima & 2nd Author \\
\hline 3 & Dr. Ummara Maqsood Sana & 3rd Author & \\
\hline
\end{tabular}

